\title{
Elisabeth Menor Natal, Talleres epigráficos Y TALLERES ESCULTÓRICOS. EL TALLER EPIGRÁFICO DEL MAESTRO SEBASTIÁN DE TOLEDO, LEÓN, ED. UNIVERSIDAD DE LEÓN, 2021, 147 PÁGS. ISBN: 978-84-18490-08-8.
}

NATALia Rodríguez SuÁREZ Universidad Complutense de Madrid

La Universidad de León, de la mano del grupo de investigación Corpus Inscriptionum Hispaniae Mediaevalium inicia una nueva andadura con la serie Minor. Esta iniciativa da continuidad y abre nuevos horizontes a la anteriormente denominada Biblioteca de Epigrafía medieval que integró títulos como: Ambrosio de Morales y la epigrafía medieval, Ángel Manrique y la epigrafía medieval o Antonio Yepes y la epigrafía medieval. El objetivo es dar visibilidad y potenciar los estudios relacionados con esta ciencia, ampliando, además, la temática a otras afines.

Esta nueva etapa nos ofrece la posibilidad de acercarnos al mundo de los talleres epigráficos medievales, gracias al esfuerzo y el trabajo realizado por una joven y prometedora investigadora, Elisabeth Menor Natal. Este estudio es fruto de sus primeros pasos en la investigación y tiene como base su trabajo fin de máster.

La necesidad y el interés de este tipo de investigaciones y la tutela de un gran especialista en la materia como es el doctor Javier de Santiago Fernández, avalan con creces su calidad científica.

El volumen que acaba de salir a la luz titulado Talleres epigráficos y talleres escultóricos. El taller epigráfico del maestro Sebastián de Toledo se estructura en doce capítulos, en los que se analiza el corpus epigráfico ligado a la obra de este escultor. La intención, con este minucioso análisis, es poder determinar la relación entre el taller epigráfico y el escultórico.

El trabajo comienza ofreciendo una breve introducción, en la que se presenta el estado de la cuestión de los estudios específicos que se han llevado a cabo sobre las oficinas lapidarias medievales. Tras esta introducción, se ofrece una sucinta semblanza del escultor, incidiendo en sus principales obras y promotores. Todo ello, para pasar después a exponer, de manera impecable, el funcionamiento de la génesis epigráfica y la relación que se observa entre los talleres epigráficos y los escultóricos, en los capítulos tercero y cuarto. 
Tras esta primera aproximación comienza el meticuloso análisis de los epígrafes relacionados de uno u otro modo con la figura de Sebastián de Toledo. Para ello, la autora ha acudido al método paleográfico. Así, en el capítulo 5, se realiza un profuso estudio de los tipos de escritura, las abreviaturas, los nexos, los signos complementarios, el surco y la decoración, la relación modular y el estudio detallado de cada una de las grafías de los alfabetos utilizados. Esto permite a la joven autora determinar unas primeras conclusiones acerca de la presencia de varias manos en la realización de los epígrafes. La crítica interpretativa que la autora realiza le permite superar la mera descripción y explicar el funcionamiento de los talleres epigráficos medievales; en este caso, tomando como foco del estudio lo que sucede en el entorno de un escultor de la categoría de Sebastián de Toledo.

Exploración que se completa, en el capítulo 7, con un análisis de los caracteres internos, en especial a través de sus fórmulas. Con este estudio formulístico se logra enriquecer el estudio paleográfico a través de la atención prestada a los caracteres internos.

El taller de Sebastián de Toledo se extendió por Toledo, Guadalajara, Cuenca o Ciudad Real. Esta movilidad ofrece a la autora la posibilidad, además, de observar si el traslado del taller escultórico supone el traslado del taller epigráfico, lo que evidenciaría si este estaba o no integrado en el taller escultórico.

Pero Elisabeth Menor no se ha limitado a estudiar solo estos epígrafes, sino que en el capítulo 6, en un intento de contextualizar los talleres epigráficos relacionados con la figura de Sebastián de Toledo, analiza también epígrafes coetáneos a ellos localizados en los mismos entornos. Ello permite comprobar cómo los talleres epigráficos que se vinculan a Sebastián de Toledo, en ciertas ocasiones, están trabajando también para otros escultores o en proyectos lapidarios en las mismas ubicaciones.

Dando un paso más, en el capítulo 7, la autora extiende su estudio a otras piezas epigráficas relacionadas con artistas que trabajaron o colaboraron con Sebastián de Toledo. Con ello, pretende comprobar si la colaboración artística suponía o no la relación o conexión entre talleres epigráficos.

Toda la comparativa hecha permite a la autora llegar a ciertas conclusiones que pretenden ahondar en el estudio de los talleres epigráficos medievales y que se recogen, a modo de conclusión, en el capítulo 9.

Este pormenorizado estudio viene acompañado de gráficos, tablas y formularios que ayudan al lector a entender y acercarse al estudio de los caracteres externos e internos de los epígrafes.

La obra se completa con un corpus epigráfico y otro fotográfico y concluye con la bibliografía utilizada.

La descripción ofrecida evidencia el interés de la obra de Elisabeth Menor Natal, no solo para el campo de la epigrafía en general, sino que resulta también relevante para otras materias como la Historia, la Historia del Arte o la Filología entre otras. Es por ello que nos debemos de felicitar por la iniciativa que ahora se abre con esta serie Minor, y esperemos que sea el primero de otros muchos trabajos en esta línea. 